\title{
Forecasting Inflation Rate of Zambia Using Holt's Exponential Smoothing
}

\author{
Stanley Jere*, Mubita Siyanga \\ Department of Mathematics and Statistics, Mulungushi University, Kabwe, Zambia \\ Email: "sjere@mu.ac.zm
}

Received 8 October 2015; accepted 24 April 2016; published 27 April 2016

Copyright (C) 2016 by authors and Scientific Research Publishing Inc.

This work is licensed under the Creative Commons Attribution International License (CC BY). http://creativecommons.org/licenses/by/4.0/

(c) (i) Open Access

\begin{abstract}
In this paper, the Holt's exponential smoothing and Auto-Regressive Integrated Moving Average (ARIMA) models were used to forecast inflation rate of Zambia using the monthly consumer price index (CPI) data from May 2010 to May 2014. Results show that the ARIMA $((12), 1,0)$ is an adequate model which best fits the CPI time series data and is therefore suitable for forecasting CPI and subsequently the inflation rate. However, the choice of the Holt's exponential smoothing is as good as an ARIMA model considering the smaller deviations in the mean absolute percentage error and mean square error. Moreover, the Holt's exponential smoothing model is less complicated since you do not require specialised software to implement it as is the case for ARIMA models. The forecasted inflation rate for April and May, 2015 is 7.0 and 6.6 respectively.
\end{abstract}

\section{Keywords}

Inflation, Holt's Exponential Smoothing, Forecasting, Consumer Price Index, Mean Square Error and Mean Absolute Percentage Error

\section{Introduction}

According to Ref. [1], inflation is a persistent rise in the general price levels of goods and services in an economy over a period of time. Inflation has been one of the most economic challenges in the world, especially in developing countries. Zambia has been facing this challenge for so many years now. Keeping inflation at a low level has been one of the major goals of economic policymakers around the globe. The maintenance of price stability is one of the macroeconomic challenges that the Zambian government has been facing since its independence which is now 50 years ago. According to Ref. [2], Zambia's inflation rate was recorded at 7.8\% in May of 2014, and averaged 9.45\% from 2005 until 2014, reaching an all time high of 19.20\% in April 2005 and a record of 6\% was

\footnotetext{
${ }^{*}$ Corresponding author.
} 
reported in December 2011 and in February 2012.

Zambia's overall economic performance has strengthened since mid 2000 after two decades of high inflation and low economic growth, reflecting sharply improved fiscal and monetary policies and progress in structural reforms. Having achieved single digit inflation, Zambia will need to consider how best to manage monetary policy in a low moderate inflation environment. Under the authorities' current regime, based on monetary targeting and exchange rate flexibility, monetary and fiscal restraint successfully reduced inflation. The Zambian authorities plan to reform their monetary policy framework. They are considering a gradual shift from strict monetary targets to a framework that would use interest rates as the main instruments to anchor inflationary expectations, perhaps leading eventually to an explicit inflation targeting regime. While inflation has been reduced under the current framework, the authorities remain concerned about persistently high bank lending rates [3].

The proposed research study actually intends to model long term behaviour of monthly inflation rate data of Zambia from May 2010 to May 2014 and predict future values. This research study actually attempts to provide information to policy makers to enable them make better decisions about the future and increase to the existing human stock of knowledge from which will be able to generate new insights and ideas about inflation.

\section{Methodology}

\section{Holt's Exponential Smoothing}

Holt's exponential smoothing is another modeling technique (not based on the ARIMA approach) that uses only a linear combination of the previous values of a series for modeling and generating future values. Given that only previous values of the series of interest are used, the only question remaining is how much weight should be attached to each of the previous observations. Recent observations would be expected to have the most power in helping to forecast future values of a series [4].

Let $Y_{1}, Y_{2}, \cdots, Y_{n}$ be a set of observations on a non-seasonal time series.

The Holt's exponential smoothing forecast is based on the assumption of a model consisting of a trend. We use the following procedure to forecast non-seasonal series.

1) The first step is to obtain the level estimate and trend estimate represented by $\hat{Y}_{t}$ and $T_{t}$ respectively as

$$
\hat{Y}_{2}=Y_{2}, \quad T_{2}=Y_{2}-Y_{1} .
$$

These can also be estimated by fitting a least squares trend line to half of the historical data.

Here $y$ intercept is $\hat{Y}_{0}$ and slope is $T_{0}$.

$$
\begin{array}{ll}
\hat{Y}_{t}=(1-\alpha)\left(\hat{Y}_{t-1}-T_{t-1}\right)+\alpha Y_{t}, & (0<\alpha<1 ; t=1,2, \cdots, n) . \\
T_{t}=(1-\beta) T_{t-1}+\beta\left(\hat{Y}_{t}-\hat{Y}_{t-1}\right), \quad(0<\beta<1 ; t=1,2, \cdots, n) .
\end{array}
$$

The values of $\alpha$ and $\beta$ that minimizes the Mean Square Error (MSE) is preferred and these values will be calculated using the solver in excel.

2) The forecasts of future values $Y_{n+h}$ of the series can be obtained by

$$
\hat{Y}_{n+h}=\hat{Y}_{n}+h T_{n}, \quad(h=1,2,3, \cdots),
$$

where $h$ is the number of periods in the future.

\section{Literature Review}

Inflation is one of the most important macroeconomic variables in an economy, no wonder there is a good number of research works that have been conducted on this topic. Most of these research works have been on modeling and forecasting inflation rates, and also investigating the performance of these models. The Auto-Regressive Integrated Moving Average model (ARIMA) has turned out to be the most commonly used model for forecasting inflation.

Ref. [5] looked at the application of SARIMA model which is an extension of ARIMA models, to forecast or predict inflation rate in Ghana. In their paper they studied Seasonal Auto-Regressive Integrated Moving Average model (SARIMA) to forecast inflation rate, where they used monthly inflation rate data. Having satisfied all the model assumptions, ARIMA $(1,1,1)(0,0,1)_{12}$ model was judged to be the best model for forecasting (Aidoo, 2010). Their results revealed that there was a decreasing pattern of inflation rate over the forecasted period. 
A recent paper done by Ref. [6] used two methods of time series to forecast inflation rate and economic growth of Pakistan. In their paper, the first method they used was Decomposition which is one of the simple and basic methods for forecasting. Decomposing the time series actually means breaking the time series into four components i.e. cycle, trend, seasonal, and irregular. Their second method was based on ARIMA models. They compared the forecasting ability of Decomposition method and the ARIMA model. They found that projecting key macroeconomic variables by applying ARIMA model on overall series gives better result than projecting components of the series and then aggregating to obtain overall forecast.

Ref. [7] did a research which examines threshold effects of inflation on economic growth for the Zambian economy using quarterly data collected between 1998 and 2011. This objective is tackled through the use of a threshold autoregressive (TAR) model and the conditional least squares (CLS) estimation technique. As a byproduct of utilizing this estimation technique, the paper is able to identify whether there could be an optimal inflation level at which the adverse effects of inflation on economic growth are subdued, or similarly, a level of inflation at which the positive effects of inflation on economic growth are maximized. In this respect, the paper estimates an inflation threshold level of $22.5 \%$ for the observed data. These results indicate that economic growth in Zambia can be stimulated even in a moderately high inflation environment. Particularly, the causality analysis identifies the credit sector and exchange rate developments as being crucial channels towards ensuring enhanced economic performance in the Zambian economy.

Ref. [8] researched on historical monthly national consumer price indices data from (March 2001-August 2011) of Bangladesh was used to forecast inflation rate. The study summarizes the steps for forecasting when using Box-Jenkins autoregressive integrated moving average (ARIMA) time series model. For forecasting one year ahead consumer price index of Bangladesh a structure for ARIMA forecasting model, where a time series was expressed in terms of past values of itself plus current and lagged values of a "white noise" error term was drawn up. And the Validity of the model was tested using standard statistical techniques and the best model was proposed which was (AR1, SAR 12) on the basis of various diagnostic and selection \& evaluation criteria.

Ref. [9] studied the performance of the GARCH Models in forecasting inflation rate for Tanzania. In particular the theory of univariate non linear time series analysis was explored and applied to the inflation data spanning from January 1997 to December 2010. The autoregressive conditional heteroscedastic (ARCH) (with their extensions to the generalized ARCH (GARCH)) models were fitted to the data. A best fitting model was selected based on how well the model captures the stochastic variation in the data. The goodness of fit was assessed through the Akaike information criteria (AIC), Bayesian information criteria (BIC) and standard error (SE): Based on minimum AIC and BIC values, the best fit GARCH models tend to be GARCH $(1 ; 1)$ and GARCH $(1 ; 2)$ : After estimation of the parameters of selected models, a series of diagnostic and forecast accuracy test were performed. Having satisfied with all the model assumptions, GARCH $(1 ; 1)$ model was judged to be the best model for forecasting. Based on the selected model, they forecasted twelve (12) months inflation rates of Tanzania in-sample period (that is from January 2010 to December 2010). From the results, it has been observed that the forecasted series are close to the actual series.

Ref. [10] estimated a range of single-equation models of inflation for Australia. They were trying to find the traditional models, such as the expectations-augmented standard Phillips curve or mark-up models, outperform the more micro-founded New-Keynesian Phillips curve (NKPC) in explaining trimmed mean inflation, both in terms of in-sample fit and significance of coefficients. This in large part reflects the weak instruments problem in the estimation of the NKPC, and is partly corrected by including a direct measure of inflation expectations, but they still found that the unemployment rate or growth in marginal costs (unit labour cost and import prices) provides a better fit than either the output gap or level of real marginal costs. These traditional models also perform well in out-of-sample tests, relative to alternative models and some common benchmarks, with the standard Phillips curve clearly superior to these benchmarks on this test. As inflation has become better anchored and hence less variable, the magnitude of the errors of the single-equation models has declined, although the explanatory power (in terms of R-squared) has fallen together with this greater stability. They also investigated the empirical importance of some other variables that are commonly cited as determinants of inflation, and find little evidence that either commodity prices or the growth rate of money directly influence Australian underlying inflation.

Ref. [11] in their research paper aimed at forecasting the inflation rate in Nigeria using Jenkins approach. The data used for this paper was yearly data collected for a period of 1961-2010. Differencing method was used to obtain stationary process. After analyzing the data using the Jenkins approach, ARIMA $(1,1,1)$ model was selected to be the one which best fitted the data. The model developed was used to forecast the year 2011 inflation 
rate as $16.27 \%$. Based on this result, they recommend effective fiscal policies aimed at monitoring Nigeria's inflationary trend to avoid the consequences in the economy.

\section{Data Analysis}

The analysis begins with the plotting of the given sequence of observations against time, this actually gives us an idea about the characteristics of the series which intern will help in detecting the presence of a trend and also in knowing if the series is stationary or non stationary. The data used in the analysis is that of the monthly consumer price index (CPI) that ran from May 2010 to May 2014. The source of the data is the Monthly Bulletin prepared by the Central Statistical Office of Zambia. With reference to the price level in 2009 (i.e. base year 2009=100).

The data consists of 49 observations of monthly consumer price index (CPI) data from May 2010 to May 2014 as shown in Table 1.

It can seen from Figure 1 that the plotted time series has a strong increasing or upward trend.

\subsection{Exponential Smoothing Model}

The time series plot of consumer price index (CPI) for Zambia plotted in Figure 1 displays a trend, it has no seasonal pattern and the growth rate has been changing over time. Because of these features that exist in the series plotted in Figure 1, Holt's Exponential Smoothing Method was adopted in this research to forecast future values of inflation.

Firstly, we obtained the initial estimates of $L_{0}$ and $T_{0}$ by fitting a least squares trend line to approximately half of the historical data as shown below in Table 2.

$$
F_{t}=L_{0}+T_{0} t
$$

Table 1. Data on consumer price index for the period of May 2010 to May 2014.

\begin{tabular}{|c|c|c|c|c|c|}
\hline Month & M_CPI & Month & M_CPI & Month & M_CPI \\
\hline 5/31/2010 & 107.74 & $11 / 30 / 2011$ & 116.94 & $5 / 31 / 2013$ & 130.67 \\
\hline 6/30/2010 & 107.93 & $12 / 31 / 2011$ & 117.47 & 6/30/2013 & 131.13 \\
\hline $7 / 31 / 2010$ & 108.45 & $1 / 31 / 2012$ & 118.77 & 7/31/2013 & 131.99 \\
\hline 8/31/2010 & 109.45 & 2/29/2012 & 119.09 & 8/31/2013 & 132.87 \\
\hline 9/30/2010 & 109.72 & 3/31/2012 & 120.84 & 9/30/2013 & 133.41 \\
\hline $10 / 31 / 2010$ & 109.44 & 4/30/2012 & 121.63 & $10 / 31 / 2013$ & 133.40 \\
\hline $11 / 30 / 2010$ & 109.92 & 5/31/2012 & 122.11 & $11 / 30 / 2013$ & 133.82 \\
\hline $12 / 31 / 2010$ & 110.86 & 6/30/2012 & 122.16 & $12 / 31 / 2013$ & 135.08 \\
\hline 1/31/2011 & 111.61 & 7/31/2012 & 123.06 & $1 / 31 / 2014$ & 136.32 \\
\hline 2/28/2011 & 112.36 & 8/31/2012 & 124.11 & $2 / 28 / 2014$ & 136.96 \\
\hline 3/31/2011 & 113.56 & 9/30/2012 & 124.74 & 3/31/2014 & 138.67 \\
\hline $4 / 30 / 2011$ & 114.24 & 10/31/2012 & 124.80 & $4 / 30 / 2014$ & 139.61 \\
\hline 5/31/2011 & 114.56 & 11/30/2012 & 125.04 & $5 / 31 / 2014$ & 140.85 \\
\hline 6/30/2011 & 114.52 & $12 / 31 / 2012$ & 126.08 & & \\
\hline 7/31/2011 & 115.89 & $1 / 31 / 2013$ & 127.08 & & \\
\hline 8/31/2011 & 116.60 & 2/28/2013 & 127.30 & & \\
\hline 9/30/2011 & 117.01 & 3/31/2013 & 128.81 & & \\
\hline 10/31/2011 & 116.80 & 4/30/2013 & 129.57 & & \\
\hline
\end{tabular}

Source: Central Statistical Office of Zambia (CSO). 


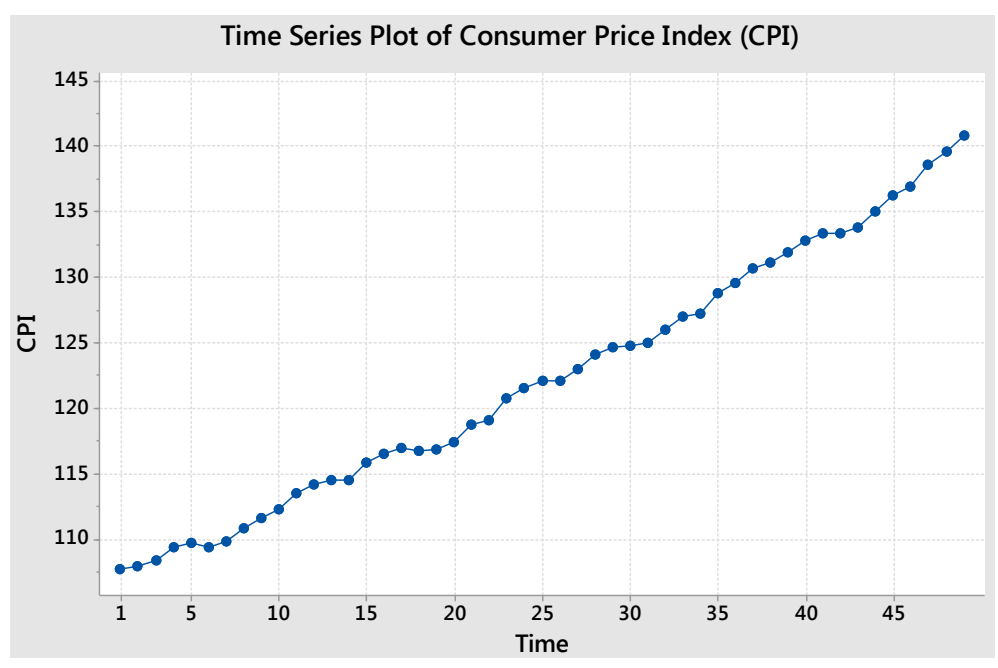

Figure 1. Time series plot of Consumer Price Index (CPI) of Zambia.

Table 2. Regression summary output.

\begin{tabular}{cccccc}
\hline & \multicolumn{3}{c}{ Summary output } \\
\hline Regression statistics & \multicolumn{3}{c}{ ANOVA } & \multicolumn{2}{c}{ Coefficients } \\
\hline Multiple R & 0.991622 & & $d f$ & Intercept & 106.63 \\
R square & 0.983315 & Regression & 1 & X Variable 1 & 0.58771304 \\
Adjusted R square & 0.982557 & Residual & 22 & & \\
Standard error & 0.553501 & Total & 23 & & \\
Observations & 24 & & & \\
\hline
\end{tabular}

where $L_{0}$ is the $y$ intercept and $T_{0}$ is the slope.

$$
F_{t}=106.63+0.58771304 t
$$

Secondly, The calculations of the smoothed level estimates $L_{t}$, smoothed trend estimates $T_{t}$, forecast value $F_{t}$, forecast error $\varepsilon_{t}$ and squared forecast error $\varepsilon_{t}^{2}$ at time $t$ (where $t=1,2,3, \cdots, 49$ ) were performed using predetermined values of smoothing constants $\alpha$ and $\beta$ which were set at $\alpha=0.1$ and $\beta=0.2$. Thereafter, the solver in Excel was used to find the best combination of $\alpha$ and $\beta$ that minimizes the Mean Square Error (MSE). The values of $L_{t}, T_{t}, F_{t}, \varepsilon_{t}$ and $\varepsilon_{t}^{2}$ were updated using the new values of $\alpha$ and $\beta$ (i.e. $\alpha=0.988$ and $\beta=0.047236$ ) which were chosen based on the combination that minimizes the root mean squared error (RMSE) and mean absolute percentage error (MAPE). The fitted model was found to be;

$$
\begin{gathered}
L_{t}=0.0120\left(L_{t-1}+T_{t-1}\right)+0.9880 Y_{t}, \quad(0<\alpha<1 ; t=1,2, \cdots, n) \\
T_{t}=0.952764 T_{t-1}+0.047236\left(L_{t}-L_{t-1}\right), \quad(0<\beta<1 ; t=1,2, \cdots, n) \\
F_{n+h}=L_{n}+h T_{n}, \quad(h=1,2,3, \cdots)
\end{gathered}
$$

where $h$ is the number of periods in the future. The calculation for the RMSE and MAPE are given below;

$$
\begin{aligned}
& \text { MAPE }=\frac{1}{n} \sum_{t=0}^{n} \frac{\left|Y_{t}-F_{t}\right|}{Y_{t}}=\frac{16.09616}{49}=0.328493 \\
& \mathrm{MSE}=\frac{1}{n} \sum_{t=0}^{n}\left(Y_{t}-F_{t}\right)^{2}=\frac{11.5588}{49}=0.235894
\end{aligned}
$$




$$
\mathrm{RMSE}=\sqrt{0.235894}=0.485689 .
$$

The updated values of $L_{t}, T_{t}, F_{t}, \varepsilon_{t}$ and $\varepsilon_{t}^{2}$ were then summarized and shown in Table 3 below.

Forecasting with the Holt's Exponential Smoothing Model

12 steps ahead forecast was made at time $t$ for consumer price index (CPI) and then the inflation rate was calculated using the forecasted CPI. The formulas below were used in the calculations of the forecasted $h$ steps ahead $\mathrm{CPI}$ and inflation rate respectively.

$$
F_{n+h}=L_{n}+h T_{n} \quad \text { and } \quad I_{t}=\frac{P_{t}-P_{t-1}}{P_{t-1}} \times 100
$$

where $P_{t}$ is the current forecasted CPI, $P_{t-1}$ is the actual CPI a year ago and $h$ is the number of steps ahead.

\begin{tabular}{|c|c|c|c|c|c|c|}
\hline & $\alpha$ & $\beta$ & MSE & RMSE & MAPE & $n$ \\
\hline & 0.988000 & 0.047236 & 0.235894 & 0.485689 & 0.328493 & 49 \\
\hline \multirow[t]{2}{*}{ S. No } & $Y_{t}$ & Level $\left(L_{t}\right)$ & Growth rate & $\begin{array}{l}\text { Forecast made } \\
\text { last period }\end{array}$ & Forecast error & $\begin{array}{c}\text { Squared forecast } \\
\text { error }\end{array}$ \\
\hline & & & $\left(T_{t}\right)$ & $F_{t}$ & $\varepsilon_{t}$ & $\varepsilon_{t}^{2}$ \\
\hline 0 & & 106.63 & 0.5877 & & & \\
\hline 1 & 107.74 & 107.7337 & 0.6121 & 107.2177 & 0.5223 & 0.2728 \\
\hline 2 & 107.93 & 107.9350 & 0.5927 & 108.3458 & -0.4158 & 0.1729 \\
\hline 3 & 108.45 & 108.4509 & 0.5890 & 108.5277 & -0.0777 & 0.0060 \\
\hline 4 & 109.45 & 109.4451 & 0.6082 & 109.0400 & 0.4100 & 0.1681 \\
\hline 5 & 109.72 & 109.7240 & 0.5926 & 110.0533 & -0.3333 & 0.1111 \\
\hline 6 & 109.44 & 109.4505 & 0.5517 & 110.3166 & -0.8766 & 0.7685 \\
\hline 7 & 109.92 & 109.9210 & 0.5479 & 110.0022 & -0.0822 & 0.0068 \\
\hline 8 & 110.86 & 110.8553 & 0.5661 & 110.4689 & 0.3911 & 0.1530 \\
\hline 9 & 111.61 & 111.6077 & 0.5749 & 111.4214 & 0.1886 & 0.0356 \\
\hline 10 & 112.36 & 112.3579 & 0.5832 & 112.1827 & 0.1773 & 0.0314 \\
\hline & & & & & & .......... \\
\hline 39 & 131.99 & 131.9877 & 0.6761 & 131.7998 & 0.1902 & 0.0362 \\
\hline 40 & 132.87 & 132.8675 & 0.6858 & 132.6639 & 0.2061 & 0.0425 \\
\hline 41 & 133.41 & 133.4117 & 0.6791 & 133.5533 & -0.1433 & 0.0205 \\
\hline 42 & 133.4 & 133.4083 & 0.6468 & 134.0908 & -0.6908 & 0.4772 \\
\hline 43 & 133.82 & 133.8228 & 0.6359 & 134.0551 & -0.2351 & 0.0553 \\
\hline 44 & 135.08 & 135.0725 & 0.6649 & 134.4587 & 0.6213 & 0.3860 \\
\hline 45 & 136.32 & 136.3130 & 0.6921 & 135.7374 & 0.5826 & 0.3394 \\
\hline 46 & 136.96 & 136.9605 & 0.6899 & 137.0051 & -0.0451 & 0.0020 \\
\hline 47 & 138.67 & 138.6578 & 0.7375 & 137.6505 & 1.0195 & 1.0394 \\
\hline 48 & 139.61 & 139.6074 & 0.7475 & 139.3953 & 0.2147 & 0.0461 \\
\hline 49 & 140.85 & 140.8441 & 0.7706 & 140.3550 & 0.4950 & 0.2451 \\
\hline
\end{tabular}

Table 3. Holt's exponential smoothing calculations for CPI. 


$$
\begin{gathered}
F_{49+1}=F_{50}=140.8441+1 \times 0.7706=141.6147, I_{50}=\frac{141.6147-131.13}{131.13} \times 100=8.0 \\
F_{49+2}=F_{51}=140.8441+2 \times 0.7706=142.3854, I_{51}=\frac{142.3854-131.99}{131.99} \times 100=7.9 \\
\vdots \\
F_{49+12}=F_{61}=140.8441+12 \times 0.7706=150.0919, I_{61}=\frac{150.0919-140.85}{140.85} \times 100=6.6
\end{gathered}
$$

Table 4 below summarizes the forecasting results of Inflation rate for one year ahead forecast from June 2014 to May 2015 using the Holt’s Double Exponential Smoothing method.

Figure 2 below displays the time plot of the actual, fitted and one year forecast for Consumer Price Index (CPI) using the Holt's double exponential smoothing with 95\% confidence interval. It can be seen that all the forecasted values fall within the confidence interval which shows the level of accuracy.

Table 4. Forecast of Consumer Price Index (CPI) using Holt’s exponential smoothing.

\begin{tabular}{ccccc}
\hline S. No & Year & Month & Forecast of CPI Holt's & Forecast of inflation rate \\
\hline 1 & 2014 & June & 141.6147 & 8 \\
2 & & July & 142.3854 & 7.9 \\
3 & & 143.156 & 7.7 \\
4 & August & 143.9267 & 7.9 \\
5 & September & 144.6973 & 8.5 \\
6 & October & 145.468 & 8.7 \\
7 & November & 146.2386 & 7.3 \\
8 & & 147.0099 & 7.9 \\
9 & & December & 7.1 \\
10 & January & 147.7799 & 7 \\
11 & & February & 148.5506 & 6.6 \\
MAPE & March & 149.3212 & 7.1 \\
RMSE & April & 150.0919 & $\mathbf{0 . 3 2 8 5}$ & \\
\hline
\end{tabular}

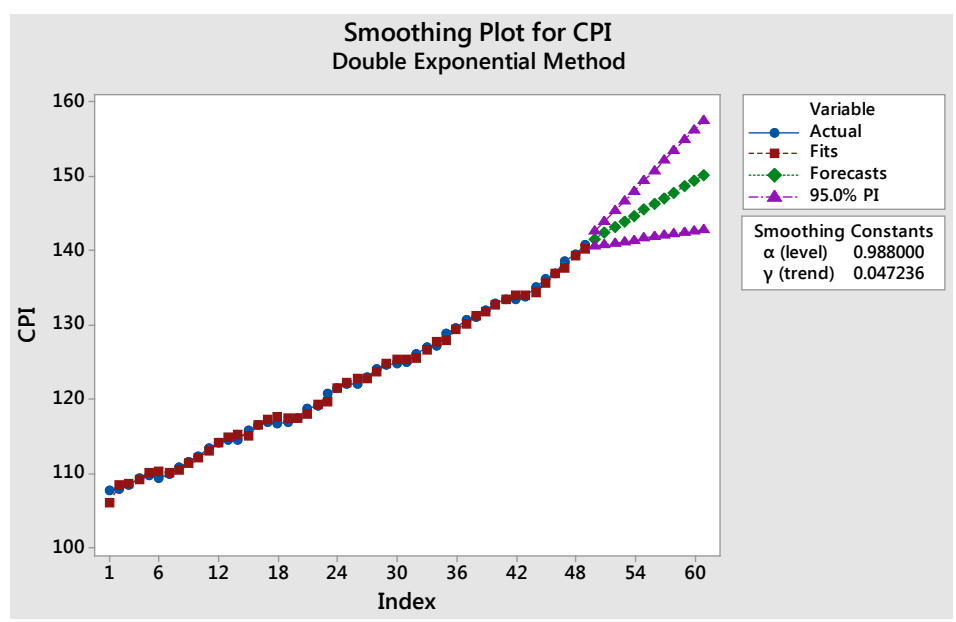

Figure 2. Smoothing plots for CPI using the Holt's double exponential smoothing method. 


\subsection{ARIMA Model}

After applying the Box Jenkins Methodology, an ARIMA ((12), 1, 0) model was chosen to be adequate using Statistical Analysis System (SAS) software [12].

Using $B$, backshift operator, the mathematical form of the estimated model is

$$
(1-B) C P I=0.70115+\frac{e_{t}}{1-0.75619 B^{12}}
$$

\section{Forecasting with the ARIMA ((12), 1, 0) Model}

Table 5 below summarizes the forecasting results of the CPI from the period of June 2014 to May 2015 and their corresponding inflation rates which were calculated using the forecasted CPI values.

Table 6 shows smaller deviations in the forecast of inflation between the Holt's and ARIMA model.

\section{Discussion}

Inflation rate poses significant problems to a Country, i.e. to Investors (both foreign and local Investors), policy makers, and even to a community at large. Among the problems include, small notes of money losing power to operate in circulation, critical shortage of goods especially domestic products. Also, in an economy where there are high rates of inflation, Investors lose confidence in such an economy, as a result the country loses out in terms of foreign direct investment. Policy makers face difficulties in implementing their policies and perpetuate poor living conditions among the low and middle classes of the country.

\section{Conclusion}

In this study, monthly consumer price index (CPI) data of Zambia from May 2010 to May 2014 are analyzed and used to forecast inflation rate. The Holt's double exponential smoothing method and an ARIMA model were used to forecasts inflation rate. Based on the forecasted results summarized in Table 6, results show that the ARIMA $((12), 1,0)$ is an adequate model which best fits the CPI time series data and is therefore suitable for forecasting CPI and subsequently the inflation rate. However, the choice of the Holt's exponential smoothing is as good as

Table 5. ARIMA forecasting results for CPI and monthly inflation rates.

\begin{tabular}{|c|c|c|c|c|}
\hline S. No & Year & Month & Forecast of CPI & Forecast of inflation rate \\
\hline 1 & 2014 & June & 141.37 & 7.81 \\
\hline 2 & & July & 142.19 & 7.73 \\
\hline 3 & & August & 143.03 & 7.64 \\
\hline 4 & & September & 143.61 & 7.64 \\
\hline 5 & & October & 143.77 & 7.77 \\
\hline 6 & & November & 144.26 & 7.80 \\
\hline 7 & & December & 145.38 & 7.63 \\
\hline 8 & 2015 & January & 146.49 & 7.46 \\
\hline 9 & & February & 147.14 & 7.44 \\
\hline 10 & & March & 148.61 & 7.17 \\
\hline 11 & & April & 149.49 & 7.08 \\
\hline \multirow[t]{3}{*}{12} & & May & 150.60 & 6.92 \\
\hline & MAPE & & 0.22 & \\
\hline & RMSE & & 0.34 & \\
\hline
\end{tabular}


Table 6. Deviations in forecasts of inflation rates.

\begin{tabular}{|c|c|c|c|c|c|c|}
\hline Year & Month & $\begin{array}{l}\text { Forecast of } \\
\text { CPI-Holt's } \\
\text { model }\end{array}$ & $\begin{array}{l}\text { Forecast of } \\
\text { inflation rate- } \\
\text { Holt's model }\end{array}$ & $\begin{array}{l}\text { Forecast of CPI } \\
\text { ARIMA model }\end{array}$ & $\begin{array}{c}\text { Forecast of } \\
\text { inflation } \\
\text { rate-ARIMA } \\
\text { model }\end{array}$ & $\begin{array}{c}\text { Deviations in } \\
\text { forecast of } \\
\text { inflation }\end{array}$ \\
\hline \multirow[t]{7}{*}{2014} & June & 141.61 & 8 & 141.37 & 7.81 & 0.19 \\
\hline & July & 142.39 & 7.9 & 142.19 & 7.73 & 0.17 \\
\hline & August & 143.16 & 7.7 & 143.03 & 7.64 & 0.06 \\
\hline & September & 143.93 & 7.9 & 143.61 & 7.64 & 0.26 \\
\hline & October & 144.7 & 8.5 & 143.77 & 7.77 & 0.73 \\
\hline & November & 145.47 & 8.7 & 144.26 & 7.80 & 0.90 \\
\hline & December & 146.24 & 8.3 & 145.38 & 7.63 & 0.67 \\
\hline \multirow[t]{5}{*}{2015} & January & 147.01 & 7.8 & 146.49 & 7.46 & 0.34 \\
\hline & February & 147.78 & 7.9 & 147.14 & 7.44 & 0.46 \\
\hline & March & 148.55 & 7.1 & 148.61 & 7.17 & $(0.07)$ \\
\hline & April & 149.32 & 7 & 149.49 & 7.08 & $(0.08)$ \\
\hline & May & 150.09 & 6.6 & 150.60 & 6.92 & $(0.32)$ \\
\hline MAPE & & 0.33 & & 0.22 & & 0.11 \\
\hline RMSE & & 0.49 & & 0.34 & & 0.15 \\
\hline
\end{tabular}

an ARIMA model considering the smaller deviations in the MAPE and RMSE. Moreover, the Holt's exponential smoothing model is less complicated since you do not require specialised software to implement it as is the case for ARIMA models. The forecasted inflation rate for April and May, 2015 is 7.0 and 6.6 respectively.

\section{Acknowledgements}

The authors are thankful to Central Statistical Office (CSO) for providing the data which was used in this research, Department of Mathematics and Statistics, Mulungushi University for using their resources and to all the people who helped in making comments on this paper.

\section{References}

[1] Omekara, C.O., Ekpenyong, E.J. and Ekerete, M.P. (2013) Modeling the Nigerian Inflation Rates Using Periodogram and Fourier Series Analysis. CBN Journal of Applied Statistics, 4.

[2] Central Statistical Office of Zambia (CSO) (2014) Monthly Bulletin, Vol. 135. http://www.zamstats.gov.zm

[3] Jahan, S., Maehle, N. and McDonald, B. (2011) Zambia: Ex Post Assessment of Longer-Term Program EngagementUpdate. IMF Country Report No. 11/197.

[4] Chris Brooks (2008) Introductory Econometrics for Finance. 2nd Edition, Cambridge.

[5] Aidoo, E. (2010) Modelling and Forecasting Inflation Rates in Ghana: An Application of SARIMA Models.

[6] Kishwer, S., Adila, R., Nighat, M., Sajida, A. and Saghir, P.G. (2013) Forecasting Inflation and Economic Growth of Pakistan by Using Two Time Series Methods. International Journal of Business and Economics Research, 2, 174-178. http://dx.doi.org/10.11648/j.ijber.20130206.17

[7] Phiri, A. (2013) Inflation and Economic Growth in Zambia: A Threshold Autoregressive (TAR) Econometric Approach. MPRA paper No. 52093. http://mpra.ub.uni-muenchen.de/52093/

[8] Faisal, F. (2012) Forecasting Bangladesh’s Inflation Using Time Series ARIMA Models. World Review of Business Research, 2, 100-117.

[9] Ngailo, E., Luvanda, E. and Massawe, E.S. (2014) Time Series Modelling with Application to Tanzania Inflation Data. Journal of Data Analysis and Information Processing, 2, 49-59. http://dx.doi.org/10.4236/jdaip.2014.22007 
[10] Norman, D. and Richards, A. (2010) Modelling Inflation in Australia. Reserve Bank of Australia: Research Discussion Paper 2010-03.

[11] Olajide, J.T., Ayansola, O.A., Odusina, M.T. and Oyenuga, I.F. (2012) Forecasting the Inflation Rate in Nigeria: Box Jenkins Approach. IOSR Journal of Mathematics, 3, 15-19. www.iosrjournals.org

[12] SAS Institute Inc. (2014) SAS/ETS 13.2 User's Guide: The ARIMA Procedure. SAS Institute Inc., Cary. 